\title{
A Brief Analysis on the Rational Thinking of Higher Education Modernization
}

\author{
Bo $\mathrm{Wu}^{1}$, Li Liu² \\ ${ }^{1}$ School of Economics and Management, Chongqing Normal University, Chongqing, 401331, China \\ ${ }^{2}$ School of Foreign Languages, Chongqing University of Technology, Chongqing, 400054, China
}

Keywords: Higher education, Modernization, Rational thinking.

\begin{abstract}
Nowadays, under our country's rapid economic, cultural and social development situation, higher educational modernization has become the primary target and important pursuit of China's higher education development. In the process of promoting higher educational modernization, we set the highest level of international higher education and forefront achievement as our construction standard, strive to achieve this level at some stage in the future. The features and essence of higher educational modernization are not just affected by its internal factors, but determined by the combined effect of many internal and external factors. The content of higher educational modernization mainly includes the universalness, quality, structuralization, internationalization, informatization and socialization of higher education, while the realization of its internationalization is the only way to promote our country's higher educational modernization. This paper revolves around thinking on China's traditional culture education and modern culture education to make an analysis, to discuss the inner characteristics, measurement index, rationalistic consciousness and realization approach of higher educational modernization, hope to provide reference and support for the construction of higher educational modernization.
\end{abstract}

\section{Introduction}

Under the background of rapid social, era, economic and cultural development, our country's higher education is gradually on the path of modernization. Compared with western developed countries, our country's higher education starts later, stimulated by external environment, our country's modern higher education gradually developed by virtue of western developed countries' education thoughts, educational culture and educational system. Based on this, in order to promote further modernization of higher education in our country, we need to make rational thinking on higher education development direction according to our country's practical education and teaching situation, sequentially take targeted measures to realize the further development of higher educational modernization.

\section{Associative thinking on traditional culture and education}

In the rational thinking of higher educational modernization, we should think modern higher education from the perspective of Chinese traditional ideological and cultural education, analyze their relation to make clear the education development direction, to promote our country' $\mathrm{s}$ higher education de develop in the right direction. We know from the analysis on Chinese traditional education history that our country had set university and primary school early in the Xia and Shang period according to culture level at that time, which were directly managed by the nation, and divided into nationwide education and township education according to different social classes ${ }^{[1]}$.After Han Dynasty, Confucian thoughts played a dominant position in education and teaching, which had a 
profound significance on knowledge dissemination. In Wei and Jin Dynasty, turbulent political situation affected education development, until the Northern and Southern Dynasties, under the undeveloped education situation, Song and Liang still paid high attention to higher education. With the thriving of Sui Dynasty, it created "Jinshi", opened the prelude of the imperial examination system. We know from the education development situation of Tang Dynasty that its education system and teaching system were formal, which played an important function in China's education development history. Song Dynasty continued to use the education system of Tang Dynasty, after its demise, Yuan Dynasty created new discipline. Provincialism of education was appeared in Ming and Qing Dynasty, at this time, school system and imperial examination system co-existed and played a role, and governors at this time paid more attention to imperial examinations. Compared with imperial examination system, college system is still used now to provide opportunity for students and promote the further development of Chinese education.

\section{The features and essence of higher educational modernization}

Relevant researches on modernization construction have been melted into many different fields, researchers with different professional disciplines also have different research and analyze method on modernization construction. We can know from people's understanding on modernization concept that many people believe that modernization construction is industrial construction, western construction, agricultural society develops into industrial society, universal application of science and technology and son on. Analyze above four main aspects of higher education modernization we know that the essence of higher education modernization is the modernization of concept, content, equipment and management ${ }^{[2]}$.

\section{Education and teaching concept}

From the perspective of concept, in order to realize higher education modernization, we should take depth concept as an entry point, pay more attention to higher education, promote all sectors of society to understand the development trend and function of higher education, thus to help social talents' comprehensive quality get an all-round development under the support of higher education, to improve our country's social human resources use ratio. So we can say that starting from higher education and teaching concept to research is an important premise to realize the modernization construction and development of higher education.

\section{Education and teaching content}

On the premise of the further development of higher education, guaranteeing the updating and enriching of content is an important safeguard to promote higher education modernization. Under the rapid development of science and technology, we should take effective measures to guarantee the advancement and frontier of higher education, real-time update knowledge and content, perfect knowledge system, through perfecting curriculum structure to improve the integration of scientific development and curriculum content, thus to ensure curriculum teaching can be updated to push the cooperative development of science and disciplines.

\section{Education and teaching resource}

One of the major characteristics of higher education modernization is the modernization of its resource, while the modernization of higher education resource is an important embodiment of national productivity and science and technology development level. The modernization of higher education resource includes equipment modernization, talent modernization, teaching material modernization and so on. Only realizing the modernization of higher education resource can promote the construction of higher education modernization. 


\section{Education and teaching management}

In addition to above three points, another feature of higher education modernization is management modernization. Only guaranteeing the modernization of higher education management system, can promote higher education teaching realize independent information management to realize further construction and development of higher education modernization.

\section{Measurement index of higher education modernization}

With the development of society, measurement index of higher education modernization also has some changes, no matter from perspective of scale, quality, structure or input and concept. The following will analyze its measurement index from the scale, quality, structure, input and concept of higher education modernization.

\section{Scale}

The most obvious embodiment of higher education modernization is the scale extension of institutions of higher learning. The development of higher education scale shows the quantitative distribution among its service function, subject and internal structure, it is the base for higher education popularization, when gross enrollment rate is more than half, it showed the initial implementation of higher education popularization ${ }^{[3]}$.

\section{Quality}

Only when scientific research, operation management and teaching staff construction reaches international index can cultivate high quality talents. On the basis of guaranteeing higher education quality, higher education scale can give full play, can play a role in international education.

\section{Structure}

Measuring whether higher education meets modernization construction standard, we should with an eye to internal structures of higher learning institutions to measure whether its system type, function, education and teaching sites are scientific and rational, on the basis of guaranteeing the competition and organic of talent cultivation to realize the modernization of education.

\section{Input}

The input and usage of educational appropriations is the premise to promoting education development. While realizing higher education modernization should guarantee enough educational appropriations and its scientific and rational use. National finance should input higher education fund according to the principle of "three growth", that is to refer to the principle of "guarantee education fund growth be higher than the growth of regular financial income; guarantee students' per capita education cost in public finance budget grows gradually year by year; guarantee students' per capita public spending in public finance budget grows gradually year by year" to input education fund to establish diverse economic investment mechanism ${ }^{[4]}$. Only by this can promote the stable development of higher education career.

\section{Concept}

The modernization management concept of higher learning institutions has important influence on higher education modernization, it is an important premise for higher education modernization. We should start from higher learning institution leaders and education workers' concept to measure whether higher education reaches the standard and whether it is with modernization.

\section{Rationalistic consciousness of higher education modernization}

In the process of improving higher education modernization level, its quality improvement cannot leave the country's support and help. While in the process of higher education modernization 
construction, we should be with some rationalistic consciousness. Rationalistic consciousness of higher education modernization can be divided into three aspects, that are quality consciousness, innovation consciousness and international consciousness.

\section{Quality consciousness}

On the premise of enlarging higher education scale and increasing number, the country should pay attention to the quality development of higher education, put forward a certain requirement and hope. The country should require higher education to be diversified, can meet learning demands of various kinds of education group, guarantee students can receive high quality education. Quality is always a problem that developed countries pay most attention, no matter for education or other aspects, we should pay enough attention. Therefore, improving higher education quality is the primary task for the nationwide higher education work, is the most basic requirement for modernization construction.

We can know from Tang Dongsheng and Ma Luting's researches that the main embodiments that higher education improved are first, the number of people who get higher education is over that half of the total population ${ }^{[5]}$. Secondly, the country has a certain number of higher learning institutions, and promoting the national higher education modernization construction through the development of higher learning institutions. Thirdly, perfect discipline construction at the same time with higher education development, guarantee to cultivate talents for different professional fields, ensure these talents can strive for country construction and social progress.

\section{Innovation consciousness}

In order to in line with international standards and guarantee the interningity of domestic scientific research fields, we should realize innovation and reform for higher education, in the higher education modernization construction, we should be with innovation consciousness and reform consciousness. Only with reform can we make progress, only with innovation can we develop, reform and innovation are important power for social development. In different periods, reform and innovation forms are also different, in the practice, though reform and innovation are difficult, we also need continuous efforts to break through. At the current stage, various countries in the world are making reform and innovation, they determine their own reform direction according to this real situation, and continue to innovate according to their target. At the same time with achieving higher education construction progress, our country also should learn from other countries, refers to their good experience, then to apply the experiences into our own construction and show our own features, to provide strong support for our own higher education modernization construction.

\section{International consciousness}

Higher education modernization construction should be with an eye to both domestic and abroad, not only need to break ourselves, but also need to get a certain international position. We should be with high international consciousness, and apply it into the higher education modernization construction and development work, thus can promote the development of domestic higher education, to help domestic higher learning institutions be in the world frontier. In terms of talent cultivation, we should pay more attention to the cultivation of scientific researchers, high degree scholars and teaching staffs to provide human resources for higher education modernization.

\section{Measures to promote higher education modernization}

From above information we know that if we want to realize further construction and development of higher education modernization, we should start from concept, target, content and system to transfer higher education concept, to innovate its target, to update and enrich iys content, to guarantee its sound system. 


\section{Transfer higher education concept}

In the process of transferring higher education concept, we should learn goodness from Chinese traditional cultures and abandon its badness. According to era and social development situation, pay attention to students' position, to improve students' enthusiasm and initiative, deliver advance thoughts to students through all kinds of teaching activities, to cultivate their innovation thoughts and improve their innovation consciousness.

\section{Innovate higher education targets}

Higher education modernization is different from former higher education, it should combine specific situation of era development and social development to make new targets, to provide right guidance for higher education modernization and provide direction for modern talents cultivation.

\section{Update higher education content}

Under the situation that higher education target has been changed, we should also innovate its content, to make the content comply to modern talent cultivation requirement. In order to realize higher education target and realize higher education modernization, we should start from updating education content to guarantee the comprehensiveness and scientificity, to provide strong support for modern talent cultivation.

\section{Perfect higher education system}

Establishing through higher education system can make talent cultivation been guaranteed, can guarantee the order and systematicness of modern higher education. Therefore, we should establish system that comply to modern talent learning standard, make it realize scientific management, to provide strong support for higher education modernization.

\section{Conclusion}

To sum up, if we want to realize higher education modernization, we should innovate education concept, target, content, system and management. This paper summarizes the features and rational thinking of higher education modernization on the basis of analysis on it, to discuss effective measures to realize higher education modernization, hope these measures can promote the further development of higher education modernization, help it develop in the right direction.

\section{References}

[1] Cao Shuliang. Higher Education Modernization: Condition, Dimension and Path, Contemporary Educational Science, 2015(19):3-5,17.

[2] Tang Dongsheng. Promote Education Governance Modernization Set Higher Education Reform as Entry Point, People's Tribune, 2015(11):133-135.

[3] Ma Luting, Wang Jingxiu. Features and Theory Construction of Higher Education Modernization in Our Country, University Education Science, 2015(4):4-7.

[4] Qu Zhenyuan. Construction of Chinese Characteristics Higher Education Governance System and Promote Governance Ability Modernization, China Higher Education Research, 2014(1):1-4.

[5] Yan Guangcai. Modernization of Higher Education Governance System and Governance Ability, Journal of Suzhou university (Education science edition), 2014(3):1-3. 